\title{
H-SEED: VISION FOR SMART CITY
}

\author{
HAIDY M. SHEHATA ${ }^{1}$, ALI F. BAKR ${ }^{2}$ \& ASMAA HASSAN ${ }^{2}$ \\ ${ }^{1}$ Pharos University in Alexandria, Egypt \\ ${ }^{2}$ Faculty of Engineering, Alexandria University, Egypt
}

\begin{abstract}
Smart cities have always been seen as a chance to apply new digital technologies in every single detail in the life of its inhabitants, while neglecting harmful impacts of technology such as internet addiction, and related digital diseases related to the extensive use of smart technologies on the health of human beings. In light of that, this paper is a trial to start a new vision for smart cities as human-cities with regard to sustainable, environmentally-friendly, and emotionally-reliable-based aspects. This new vision could be called H-SEED (human-sustainable environmental emotional development). It assumes that establishing new indicators for this new vision, H-SEED, gives a chance to recognize how a certain city or development could be H-SEED. The main objective of this paper is to create a new scope of fifth generation smart cities called H-SEED cities which depend on a human-centric approach. It adopts an analytical deductive methodology, and is divided into two parts. First, it reviews conventional trends in smart cities through outlining their history. Second, it shows the assumed established H-SEED indicators, on an existing or new city development. It concludes several composite indicators establish social spectrum to promote human social infrastructure, promote human green infrastructure and $\mathrm{H}$ emotionality.

Keywords: smart city, human centric, smart city generations, H-SEED indicator, sustainability, emotions, economic, development, social spectrum.
\end{abstract}

\section{INTRODUCTION}

The rate of development is increasing day by day in the world with increasing population density and the subsequent development in everything. Since 1990 the term "Smart City" has been spreading in communities that have chosen for urban transformation. Governments, driven by technology providers, as leaders of the smart city movement have later understood that technology is "only" the enabler for reaching governmental, economic and societal goals.

Smart city is always being seen as a chance to apply new digital technologies in every single details in the life of its inhabitants, while neglecting harmful impacts of technology such as internet addiction, and related digital diseases related to the extensive use of smart technologies on human being health.

The objective is to create a new scope of fifth generation of smart city call H-SEED city which depend on a human-centric approach to create H-SEED indicator. It is organized as follows: the background and smart city principles in Section 2, the terms that are used in this paper are defined and the generations of smart cities In Section 3, and in Section 4 discussed according to the extracted outcomes indicators. Finally, in Section 5 some conclusions and some future thoughts are given.

\section{SMART PRINCIPLES FOR SMART CITY DEPELOPMENT}

Smart city concept has evolved over the last decade due to the increasing research on the subject, mostly influenced by new technologies and production systems. Compared to the initial idea that focused primarily on technological infrastructure [1], various identities, meanings and intentions expressed for smart cities have been segregated based on associating them with the various schools of thought, based on [2]. There are 3 approaches of thoughts addressing the SC concept: (1) generic approach, (2) terminological approach, and (3) structural approach as shown in Fig. 1. 


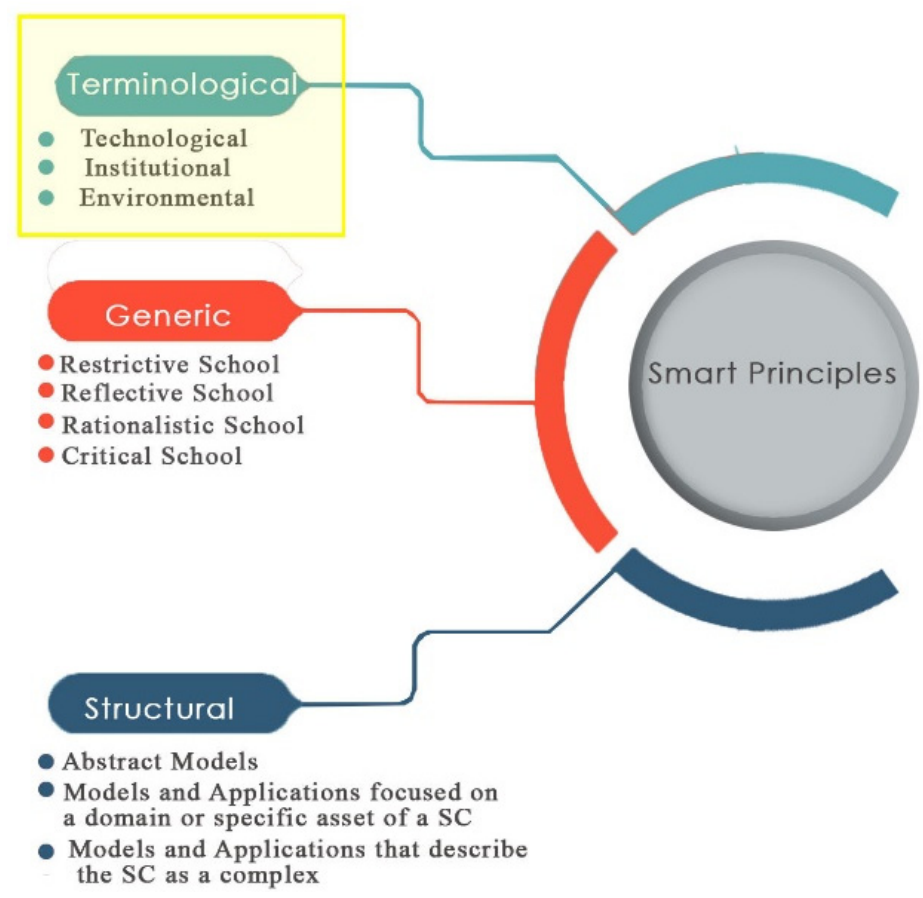

Figure 1: Smart principles for smart city approaches. (Source: Author, 2019.)

\subsection{Generic approach}

The current section divides the literature about smart cities into the 3RC framework and its four schools of thought, namely: (1) restrictive school, (2) reflective school, (3) rationalistic school, and (4) critical school [2], [3]. (1) The restrictive school is primarily oriented to technology; (2) the reflective school focuses on how technology is required to enrich human life; (3) the rationalistic school perceives SC as an integrative mechanism to mediate human interaction with technology; and (4) the critical school addresses the negative effects emerging from the way SC has been planned and implemented.

\subsection{Terminological approach}

Nam and Pardo [4] sought to outline them from three perspectives, in the technological approach, people and citizens play a less proactive role where the institutional approach, the community governance is the focal point of urban transformation; in the environmental approach, the fundamental aspect is sustainable management of natural resources; while in the human perspective, social capital is the foundation from which other urban factors are developed and implemented [4].

\subsection{Structural approach}

In the literature three types of structures that allow the empirical investigation of cities can be identified: (1) abstract models or frameworks that seek to describe the different domains and assets of a SC; (2) models and applications focused on a domain or specific asset of smart 
cities; and (3) models and applications that describe the SC as a complex. In this research will focus on the Terminological approach by Human perspective and institutional approach $[2],[5]$.

\section{GENERATIONS OF SMART CITY}

Smart cities began from the late nineteenth century in the 1850s. The most famous is the vision of a healthy and practical city. In 1904, the hydropower, car production and imaging power was cleared to the city and proved that the cities of the future must include industry and technological achievements. In Bauhaus movement in Germany (1919-1932) also attracted some ideas of mass industrial production [6], [7] then 1922 Le Corbusier produced his plans for its three million inhabitants. In the heart of the city a group of 60 skyscrapers considered the latest revolutionized the construction industry at the time, Then came the Second World War led to the development of cities and suburbs and in many cities planned as an alternative to the crowded and polluted cities [8], [9].

Modern technologies in the 1960s quickly inspired urban scientists to begin to predict what their impact would be on cities. The idea of "e-building" is a city model that embraces technology networks for social justice and creativity, in connection with natural habitats, energy economy, time and sustainability of the most important cities "Plug-in-City" designed by Peter Cook and "Walking City" as shown in Figs 2 and 3 [6], [8], [16].

Throughout the 1960s, 1970s and 1980s there was a significant stream of published work that engaged with the emerging information society on the urban scale in a visionary way. In the 1980s the idea of instrumenting the city with networks led to the popularization of "wired cities" and other related conceptions, such as "cyber cities", "information cities", "intelligent cities", "digital cities" and "virtual cities". Most of these conceptions represented visions of what cities might look like in the distant future, past the reality of what was possible at that time [10]. The accelerating technological change of that era enabled for the first time the ample spread and popularization of Information and Communication Technologies (ICTs), making them a part of everyday life. The World Wide Web facilitated networking and information transfer and the first browsers popularized the use of the Internet. By the mid1990s, many studies featured visions about future cities where ICTs would be the main enabler of democracy and city management in 1997, which introduced the term web or virtual city in an attempt to describe local ICT network initiatives, which enabled the development of local cyber-based (virtual) communities (decentralized, interactive, one-to-one and oneto-many media networks).

From 1990 to 2000 the Internet would allow people to access all goods and services from any location in the world. Allegedly, all their functions would be transferred to the digital world; thus, physical cities were pronto extinct, as the benefits of spatial agglomeration would disappear even wrote about the "Death of Distance", suggesting that distance was no longer a limiting factor for communications and transactions [6], [17]. In 2050 human will be the main role of the city (H-SEED)as a new vision on smart city world as shown in Fig. 4.

\section{H-SEED CITY}

Over the past centuries, technology has been the primary approach to the cities like Web/Virtual city, Knowledge city, Broadband city, Sustainable city, Resilient city, Mobile/Ambient city, Smart city, Digital city, Intelligent city, Ubiquitous city and Eco city approach in terms of strategies as shown in Table 1. But when you focus on the new smart city approach you will realize that technology is not considered the basis of the success of smart city but considered as a supporting factor after the human. 


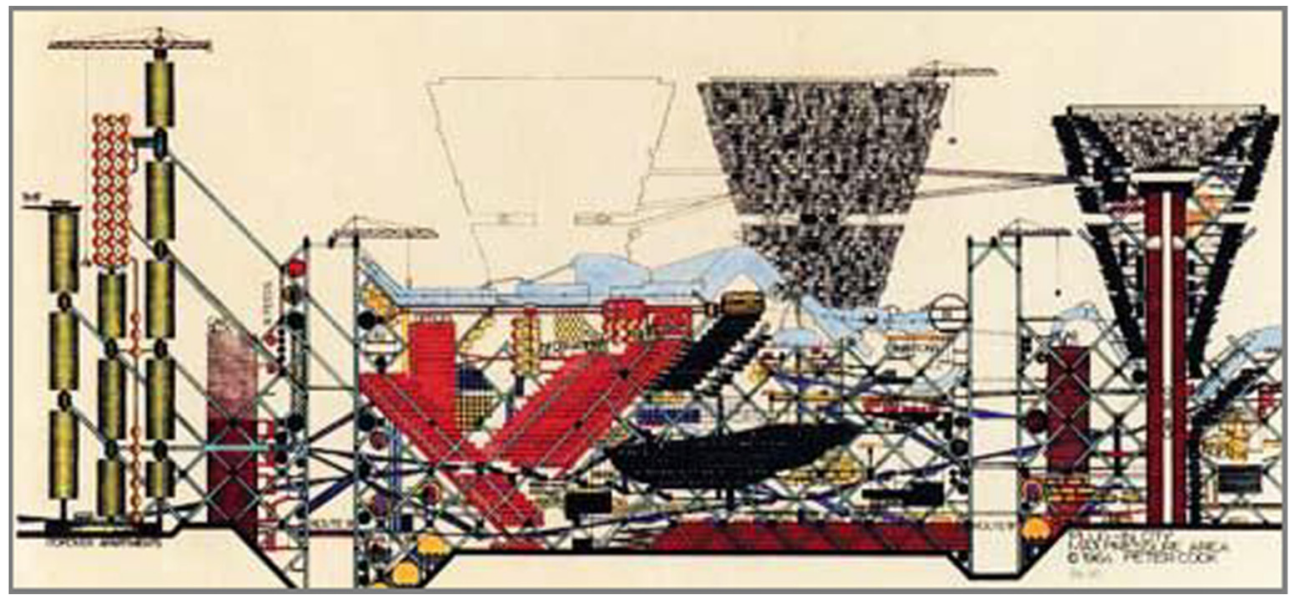

Figure 2: The "Plug-in-City", designed by Peter Cook in 1964. (Source: Angelidou [6].)

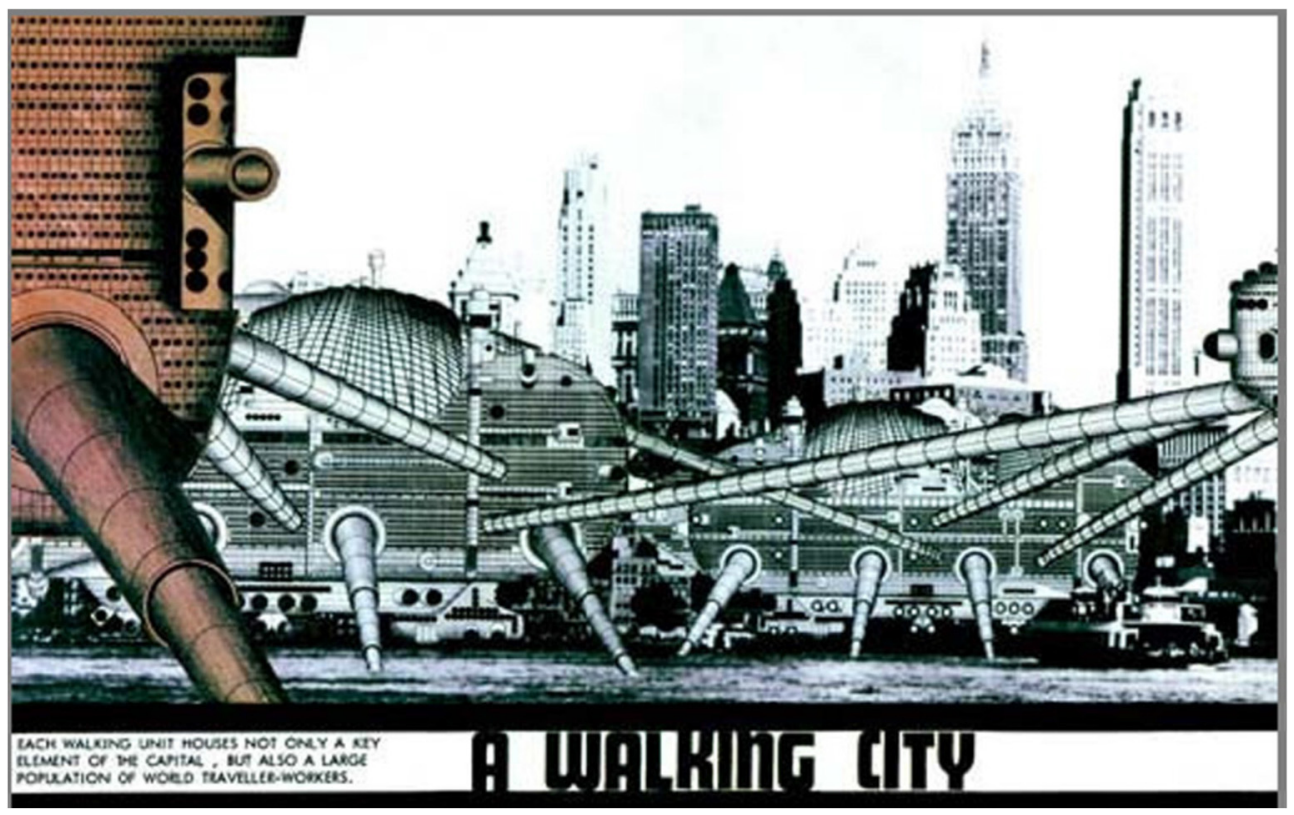

Figure 3: The "Plug-in-City", designed by Peter Cook in 1964. (Source: Phan and Qureshi [11].)

The concept of the new smart city (H-SEED) is a new Transformation in the urban model that promises to bring happiness to the lives of urban dwellers. Its main objective is to build a human-centric smart city at its foundation and to provide quality of life, economic development and environmental balance. From previous reviews along generations of smart cities as shown in Table 1, it is found that the new city includes all the objectives and elements that intersect smart cities since its inception, so that 2050 become the new smart vision. 


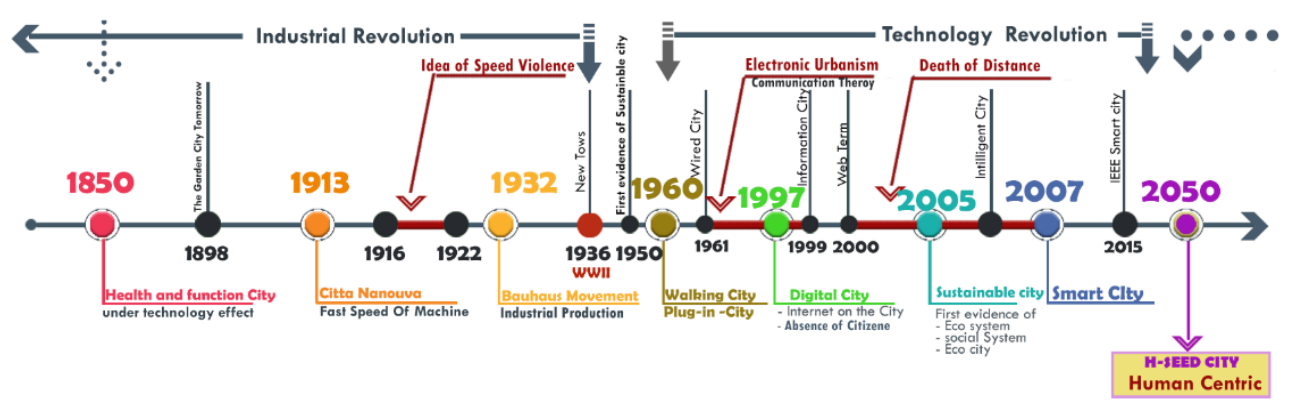

Figure 4: Generations of smart cities. (Source: Author, 2019.)

Table 1: Some of H-SEED indicators. (Source: Author, 2019.)

\begin{tabular}{|c|c|c|c|c|c|c|c|c|c|c|c|c|c|c|c|c|c|c|c|c|c|c|c|}
\hline \multirow[b]{2}{*}{ ittes } & \multicolumn{4}{|c|}{ Technological Factor } & \multicolumn{3}{|c|}{ Governance } & \multicolumn{3}{|c|}{ Environmental } & \multicolumn{11}{|c|}{ Human Factor } & \multicolumn{2}{|c|}{ Mobility } \\
\hline & 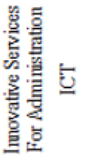 & 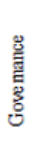 & 兽 & 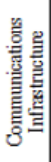 & $\frac{\widehat{d}}{2}$ & 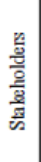 & 薦 & 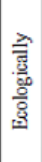 & 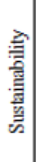 & 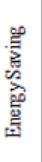 & 裹 & 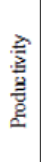 & $\begin{array}{l}\text { 펼 } \\
\text { 产 } \\
\text { 홀 }\end{array}$ & 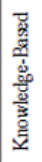 & 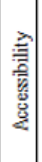 & 经 & 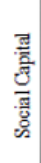 & 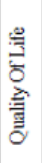 & 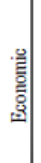 & 窟 & 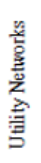 & 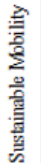 & 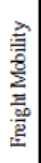 \\
\hline Virtual city & 0 & 0 & & & 8 & & & & & & & & & & & & & 0 & & & & & \\
\hline Knowledge city & & & & & & & & & & & 0 & 0 & & 0 & & 0 & & & & 0 & & & \\
\hline Broadband city & 00 & & & 0 & & & & & & & & & & & & & & & & & & & \\
\hline Sustainable city & & & & & & $a$ & 0 & 0 & 0 & 0 & & & & & & 0 & 0 & & 0 & & & & \\
\hline Resilient City & 0 & & 0 & & & & 0 & & 0 & 0 & & 0 & & & 0 & & & 0 & & & & & \\
\hline Mobile city & 00 & & & 0 & & & & & & & & & & & 0 & & & 0 & & & 0 & 0 & 0 \\
\hline Smart city & 00 & & & 0 & & 0 & & & & & & & & 0 & 0 & & 0 & 0 & & 0 & 0 & & $\circ$ \\
\hline Digital City & $\bar{O}$ & 0 & 0 & 0 & & & & & & & & & & & & & & & & & & & \\
\hline Intelligent city & 0 & 0 & 0 & & & 0 & 0 & & & & & & & & 0 & & 0 & & 0 & & & & \\
\hline Ubiqui tous city & 0 & & & 0 & & & & & & & & & & 0 & & & & 0 & 0 & & & & \\
\hline Eco city & 0 & & & & & 0 & & 0 & 0 & 0 & & & & & & 아 & & 0 & & & & 0 & \\
\hline H-SEED 2050 & - 1 & $\bullet$ & $\bullet$ & & $\bullet$ & - & - & $\bullet$ & - & - & 8 & - & $\bullet$ & e & - & e & - & e & $\bullet$ & - & - & $\bullet$ & - \\
\hline
\end{tabular}

The process of transforming the city into a complex, multidimensional and multidisciplinary exploration agreement can be summarized as a city focused on all the essential aspects of: (1) technological factor, (2) governance factor, (3) environmental, (4) human factor, and (5) mobility factor. When they include the previously mentioned factors, then it can be called "H-SEED City".

\section{INDICATORS PROCESS TO DEVELOP HIGH-QUALITY INDICATORS}

The selection of basic data should maximize the overall quality of the final result. In particular, in selecting the data the following dimensions are to be considered: (1) relevance, (2) accuracy, (3) timelines, (4) accessibility, (5) interpretability, (6) coherence, To build composite indicators some basic definitions are given at the outset [12]. These definitions have been adapted to the context of composite indicators, drawing on concepts from multicriteria decision theory and complex system theory [13], [14]. 
1. Dimension: is the highest hierarchical level of analysis and indicates the scope of objectives, individual indicators and variables. For example, a sustainability composite indicator can include economic, social, environmental and institutional dimensions.

2. Objective: indicates the desired direction of change.

3. Individual indicator: is the basis for evaluation in relation to a given objective (any objective may imply a number of different individual indicators.

4. Variable: is a constructed measure stemming from a process that represents, at a given point in space and time. A composite indicator or synthetic index is an aggregate of all dimensions, objectives, individual indicators and variables used. This implies that what formally defines a composite indicator is the set of properties underlying its aggregation convention [12], [15].

\section{H-SEED BUILDING INDICATORS}

After the describe how to create composite indicators, can be Construct H-SEED composite indicators which start the new city with a SEED as objective where Sustainable, Environmental, Emotional, and Development as dimensions and (H) Human basic individual indicator to lead the new variables (Social Spectrum, Social Environment, Human Mobility, Human Emotions) to produce H-SEED composite indicators as shown in Fig. 5.

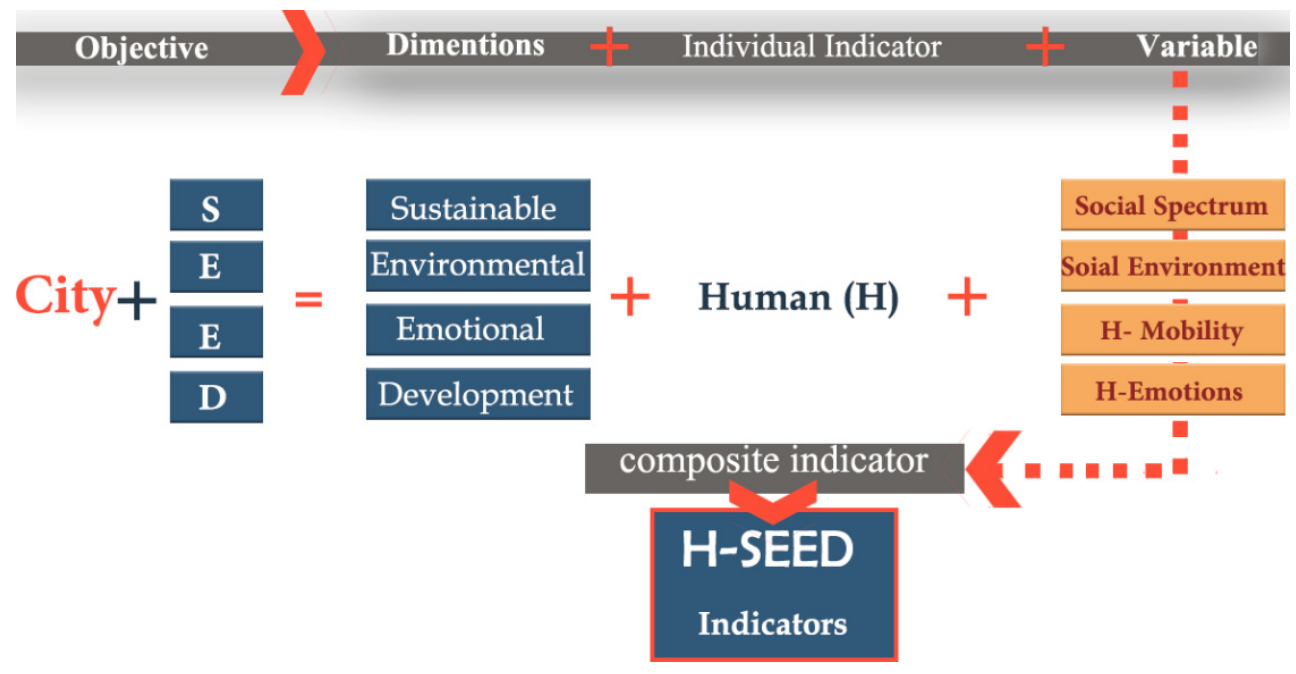

Figure 5: H-SEED Building indicators (Source: Researcher 2019.)

\section{H-SEED INDICATORS}

Table 2 shows some of the composite indicator for the new city "H-SEED" which it made up of three columns: chapters, goals and their indicators. This research will focus on some of chapters: (1) human social infrastructure, (2) human green infrastructure, and (3) human Emotion which they are considered an essential part in the development of the city. They are all known words for researchers that is why no need to review such words. 
Table 2: Some of the H-SEED indicators. (Source: Author, 2019.)

\begin{tabular}{|l|l|l|}
\hline Chapter/H-SEED & Goals & Indicators \\
\hline $\begin{array}{l}\text { 1. Social spectrum } \\
\text { infrastructure }\end{array}$ & $\begin{array}{l}\text { Goal 1: Promote accesses to } \\
\text { roads }\end{array}$ & $\begin{array}{l}\text { Key indicator 1.1: Percentage of } \\
\text { paved sidewalk } \\
\text { Key indicator1.2: Percentage of } \\
\text { road conditions }\end{array}$ \\
Goal 2: Increase park areas & $\begin{array}{l}\text { Key indicator 2.2: Percentage of } \\
\text { parks in the city }\end{array}$ \\
\hline $\begin{array}{l}\text { Promote human green } \\
\text { infrastructure }\end{array}$ & $\begin{array}{l}\text { Goal 3: Connect to social } \\
\text { activities }\end{array}$ & $\begin{array}{l}\text { clubs to the total area. Access to the } \\
\text { total area }\end{array}$ \\
\hline Promote to H-Emotionality & $\begin{array}{l}\text { Goal 5: Promote physical } \\
\text { emotion spaces }\end{array}$ & $\begin{array}{l}\text { Key indicator 4.1: Percentage of } \\
\text { waste management }\end{array}$ \\
\hline
\end{tabular}

\section{CONCLUSION}

This paper establishes H-SEED as a new vision for fifth generation of smart cities would be human-centric is a regarding sustainability, environmental-friendly, and emotional-reliablebase place to live in.

The urban futures showed that technology has always played main role in forward-looking visions about the fifth generation which technology didn't the main factor.

The new generation of new smart city should be measure human dimensions and variables of this smart city.

To test any city should be set indicators, so in this research putting some of indicators which considered main to measure any city to sure that city is an H-SEED city. It set several key points and goals, including human social infrastructure, human green infrastructure, and it has goals. As for the position of emotions, it is the highlighting of a new important point that must be applied to the new city, which includes one goal. To work on this topic, has been revised review of the smart cities and what is character of other and when did the history of each city begin to come, Time Line explains its beginning and arrives at the new city year 2050 to creation "H-SEED city" this indicator considered a sample to measure a city to be: $\mathrm{H}$-SEED. later on other research will be explaining all indicators.

\section{REFERENCES}

[1] Mahizhnan, A., Smart cities: The Singapore case. Cities, 16(1), pp. 13-18, 1999.

[2] Blanck, M., Duarte Ribeiro, J.L. \& Anzanello, M.J., A relational exploratory study of business incubation and smart cities: Findings from Europe. Cities, 88, pp. 48-58, 2019.

[3] Reddy Kummitha, R.K. \& Crutzen, N., How do we understand smart cities? An evolutionary perspective. Cities, 67, pp. 43-52, 2017.

[4] Nam T. \& Pardo, T.A., Conceptualizing smart city with dimensions of technology, people, and institutions people, and institutions. Proceedings of the 12th Annual International Conference on Digital Government Research, 2011. 
[5] Allam, Z. \& Newman, P., Redefining the smart city: Culture, metabolism and governance. Smart Cities, 1, pp. 4-25, 2015.

[6] Angelidou, M., Smart cities: A conjuncture of four forces. Cities, 47, pp. 95-106, 2015.

[7] Eremia, M., Toma, L. \& Sanduleac, M., The smart city concept in the 21 st century. Procedia Engineering, 181, pp. 12-19, 2017.

[8] Hall, P., Cities of Tomorrow: An Intellectual History of Urban Planning and Design in the Twentieth Century, Wiley, 2002.

[9] Romão, J., Kourtit, K., Neuts, B. \& Nijkamp, P., The smart city as a common place for tourists and residents: A structural analysis of the determinants of urban attractiveness. Cities, 78, pp. 67-75, 2018.

[10] Atkinson, R.D., Technological change and cities. Cityscape, 3(3), pp. 129-170, 1998.

[11] Phan, A. \& Qureshi, S.T., 5G impact on smart cities, 2017.

[12] Michela, M.. Handbook on Constructing Composite Indicators: Methodology and User Guide, OECD, 2008.

[13] UN-Habitat, Urban Indicators Guidelines “Better Information, Better Cities", 2009.

[14] Munda, G. \& Nardo, M., Constructing Consistent Composite Indicators: The Issue of Weights, European Commission, 2005.

[15] Zwanenburg, S.P., How to tie a construct to indicators: Guidelines for valid measurement. Thirty Sixth International Conference on Information Systems, Fort Worth, 2015.

[16] Barlow, J., Making the digital city: The early shaping of urban internet space. Interface: The Journal of Education, Community and Values, 6(3), 2006.

[17] Anthopoulos, L.G. \& Fitsilis, P., Evolution roadmaps for smart cities: Determining viable paths. 13th European Conference on eGovernment-ECEG, 2013. 